\title{
Análise da rentabilidade da terminação de bovinos de corte em condições de confinamento: um estudo de caso
}

\author{
[Profitability analysis of finishing beef cattle in feedlot conditions: a case study] \\ M.A. Lopes ${ }^{1}$, G.P. Magalhães ${ }^{2}$ \\ ${ }^{1}$ Departamento de Medicina Veterinária - Universidade Federal de Lavras \\ Caixa Postal 37 \\ 37200-000 - Lavras, MG \\ ${ }^{2}$ Acadêmico do curso de Zootecnia - UFLA
}

\begin{abstract}
RESUMO
Estudou-se a rentabilidade da terminação de bovinos de corte em confinamento, calculou-se o custo de produção e identificaram-se os componentes de maior influência sobre o custo operacional efetivo da arroba de carne. Os dados foram provenientes de um sistema de produção de bovinos de corte localizado no oeste do estado de Minas Gerais, no qual foram terminados em confinamento 3.583 animais, durante os meses de abril a novembro de 2002. A rentabilidade do sistema de produção foi estimada utilizando-se o software Cu\$to Bovino Corte. Os componentes do custo operacional efetivo que exerceram maior influência sobre os custos da atividade confinamento foram, em ordem decrescente: aquisição dos animais, alimentação, despesas diversas, mão-de-obra, sanidade e impostos. O confinamento do sistema de produção mostrou que a atividade tem condições de sobreviver no longo prazo.
\end{abstract}

Palavras-chave: bovinocultura de corte, análise econômica, custo de produção, índices técnicos.

\begin{abstract}
The research analyzed the profitability of beef cattle finished in feedlot, estimated the cost production and evaluated the components with most influence on effective operational costs of about 32 pounds of meat (one arroba). Data on 3,583 animals finished from April to November in feedlot were used in the analysis. The profitability of the production system was estimated by $\mathrm{Cu}$ \$ to Bovino Corte software. The factors of the effective operational system with highest influence on feedlot costs were in decreasing order: animal purchasing price, feed, miscelaneous expenses, animal health and taxes. The positive profitability suggests that finishing feedlot production system has condition to survive during long term period.
\end{abstract}

Keywords: economical analysis, beef cattle, production cost, technical indices

\section{INTRODUÇ̃̃O}

A engorda confinada proporciona lotação mais elevada que os regimes de pastejo, mas a arroba produzida em confinamento é mais cara. As vantagens do confinamento são: redução da idade de abate do animal, produção de carne de melhor qualidade, aumento do desfrute reduzindo a ociosidade dos frigoríficos na entressafra, maior giro de capital, melhor aproveitamento das áreas de pastagens para outras categorias animais e elevada produção de adubo orgânico. A diminuição da idade de abate melhora a qualidade da carne, mas não melhora a

Recebido para publicação em 21 de novembro de 2003

Recebido para publicação, após modificações, em 25 de novembro de 2004

E-mail: malopes@ufla.br 
remuneração adicional pela qualidade de produção. A única diferença no preço paga pelos frigoríficos está entre a carne de vaca e a de boi (Peixoto et al., 1988).

A análise econômica da atividade gado de corte é importante, pois o produtor passa a conhecer, com detalhes, os fatores de produção (terra, trabalho e capital). A partir de estudos dessa natureza, identificam-se os pontos de estrangulamento, que permitem concentrar esforços gerenciais e tecnológicos para se obter sucesso na atividade e atingir os objetivos de minimização de custos e maximização de lucros (Lopes e Carvalho, 2002). De acordo com Lacorte (2002), a pecuária de corte, nos últimos anos, valoriza o planejamento, o controle e a gestão produtiva e empresarial das fazendas.

Os objetivos deste trabalho foram analisar a rentabilidade da terminação de bovinos de corte em confinamento, calcular o custo de produção e identificar os componentes que exerceram maior influência sobre o custo operacional efetivo da arroba de carne.

\section{MATERIAL E MÉTODOS}

Os dados analisados são provenientes de um sistema de produção de bovinos de corte localizado no oeste do estado de Minas Gerais, cujas atividades de confinamento de bovinos foram iniciados em 1980 e, desde então, foram gradativamente ampliadas e tornaram-se mais especializadas. O confinamento dos 3.583 animais ocorreu entre os meses de abril e novembro de 2002, na época de estiagem na região, com ciclos de engorda de aproximadamente 90 dias.

A alimentação volumosa de capim-elefante (Pennisetum purpureum) e milho (Zea mays) foi produzida na própria fazenda e armazenada em silos do tipo trincheira. Foram cultivados aproximadamente 200ha de milho e 100ha de capim-elefante. No capim, foram realizados três cortes anuais, com intervalos de 60 dias, totalizando $75 \mathrm{t} /$ ha de matéria verde/ano. Após os cortes, foram realizadas adubações orgânica com esterco e inorgânica com uréia ou sulfato de amônio, em cobertura.
A aquisição de grãos e farelos foi feita no período de maior oferta da cada insumo, pois a empresa possui capacidade para estocar aproximadamente $\quad 1.000$ toneladas. Esses insumos são misturados, na propriedade, em uma fábrica de ração com capacidade de produção de 2t/hora. Para o arraçoamento foi utilizada uma misturadora alimentadora vertical Casale com capacidade de $13 \mathrm{~m}^{3}$, acoplada a um trator Valmet 985. Uma pá carregadeira Michigam Clark 75 foi utilizada no processo de desensilagem e abastecimento da alimentadora vertical.

Foi fornecida dieta total constituída de $60 \%$ de concentrado e $40 \%$ de volumoso (silagem mista de capim e milho) na matéria seca. A dieta foi distribuída quatro vezes por dia, sendo realizadas, aproximadamente, 16 viagens da misturadora alimentadora. Para a fabricação e distribuição da ração total no cocho utilizaram-se três e um funcionários, respectivamente. A mineralização completa foi fornecida na própria dieta total. $\mathrm{O}$ sal comum foi fornecido à vontade, em cochos dentro dos currais de engorda. No período de arraçoamento foram gastas 6.407 toneladas de volumoso e 2.006 toneladas de concentrado. O consumo médio diário foi de $15,8 \mathrm{~kg}$ de volumoso e $5,2 \mathrm{kgde}$ concentrado por animal. Nas Tab. 1 e 2 apresentam-se a composição da ração fornecida e a composição bromatológica da silagem.

Tabela 1. Composição da ração fornecida aos animais durante o confinamento (na matéria natural)

\begin{tabular}{lc}
\hline Ingrediente & $\%$ \\
\hline Quirela de milho & 14 \\
Polpa cítrica & 18 \\
Raspa de mandioca & 18 \\
Casca de soja & 20 \\
Girassol & 17,5 \\
Amendoim & 6 \\
Confinamix & 3 \\
Calcita & 1,8 \\
Uréia & 1,7 \\
Total & 100 \\
\hline
\end{tabular}

Os animais eram basicamente constituídos de Nelore e mestiços (sem raça definida), com média de peso de 374kg em 12,47 arrobas (@). Foram selecionados e separados em lotes quanto 
ao tamanho, grupo genético e peso. Após 45 dias, receberam uma dosagem de modificador orgânico e foram novamente pesados e separados para formar lotes uniformes. Os animais mestiços foram castrados para atender às exigências dos frigoríficos, visando a um melhor acabamento de carcaça.

Tabela 2. Composição bromatológica da silagem mista (milho e capim elefante) fornecida aos animais durante o confinamento (na matéria natural)

\begin{tabular}{lc}
\hline & Concentração (\%) \\
\hline Umidade & 81,66 \\
Matéria seca original & 18,34 \\
Proteína bruta & 6,87 \\
Extrato etéreo & 1,26 \\
Fibra bruta & 30,96 \\
Fibra detergente ácido & 35,48 \\
Fibra detergente neutro & 61,99 \\
Cinza & 6,09 \\
Cálcio & 0,37 \\
Fósforo & 0,12 \\
Nutrientes digestíveis totais & 56,67 \\
Potássio & 1,62 \\
Energia líq (mcal/kg) & 1,27 \\
\hline
\end{tabular}

As instalações (12 currais, cochos, brete, balança, tronco de contenção e embarcadouro) preenchiam os requisitos para atividades dessa natureza.

A pesquisa considerou duas etapas no levantamento das informações. Na primeira, utilizou-se um questionário e caderneta de campo para fazer o inventário completo dos bens da propriedade, com apuração do valor e vida útil de cada ativo. Foram registradas: benfeitorias, máquinas, veículos, equipamentos e implementos, ferramentas e rebanho. $\mathrm{Na}$ outra etapa, o sistema de produção foi visitado no início de cada mês para coleta de dados referentes à produção, despesas realizadas e receitas apuradas no mês anterior.
Os dados foram cadastrados no software Cu\$to Bovino Corte (Lopes et al., 2001), aplicativo utilizado para o processamento eletrônico dos dados e análise de rentabilidade do sistema de produção. O software contemplou as duas estruturas de custo de produção: custo total de produção, que envolve os custos fixo e variável, utilizada por Reis (1999), e custo operacional, proposta por Matsunaga et al. (1976).

Os itens que compuseram o custo operacional efetivo de produção do leite foram divididos em: aquisição de animais, mão-de-obra, alimentação, sanidade, impostos e despesas diversas (Lopes et al., 1999). Os índices produtivos e econômicos foram comparados por meio de análises descritivas e agrupados em tabelas, objetivando melhor comparação, discussão e apresentação dos resultados.

\section{RESULTADOS E DISCUSSÃO}

Na Tab. 3 apresenta-se um resumo da análise de rentabilidade da atividade estudada. Da receita total, R\$2.847.211,47, nada menos que $\mathrm{R} \$ 2.831 .191,17$ (Tab. 4), representando 99,4\% das receitas, foram provenientes da venda de 3.583 bovinos, totalizando 56.561,57@, ao preço médio de R\$50,06/@. O peso médio de venda foi de 15,62@, que representou um ganho médio de 3,15@ no período de engorda, com rendimento de carcaça médio de $50,5 \%$. A receita proveniente da venda de esterco, $\mathrm{R} \$ 16.020,30$ (Tab. 4), representou $0,56 \%$ do faturamento, percentual aquém dos obtidos por Lopes e Sampaio (1999), 6,8\%, Martins et al. (2002), $3,3 \%$, e Martins e Lopes (2002), 2,6\%. Este valor se justifica pelo fato de o esterco ter sido utilizado como adubo orgânico na capineiras. Isso resultou em redução da receita, mas representou diminuição nas despesas com manutenção das capineiras. 
Tabela 3. Resumo da análise de rentabilidade da terminação de bovinos de corte em confinamento

\begin{tabular}{lc}
\hline Discriminação & $\mathrm{Resultados}$ \\
\hline Receitas & $\mathrm{R} \$ 2.847 .211,47$ \\
Custo operacional total & $\mathrm{R} \$ 2.685 .290,18$ \\
$\quad$ Custo operacional efetivo (despesas) & $\mathrm{R} \$ 2.638 .503,02$ \\
Custo com depreciação & $\mathrm{R} \$ 46.787,16$ \\
Custo total & $\mathrm{R} \$ 2.790 .818,91$ \\
$\quad$ Custos fixos & $\mathrm{R} \$ 113.342,29$ \\
$\quad$ - Remuneração da terra & $\mathrm{R} \$ 33.075,00$ \\
- Remuneração sobre o capital investido & $\mathrm{R} \$ 30.390,84$ \\
- Custo com depreciação & $\mathrm{R} \$ 46.787,16$ \\
- Custo com impostos (ITR e IVA) & $\mathrm{R} \$ 3.089,29$ \\
Custos variáveis & $\mathrm{R} \$ 2.677 .476,62$ \\
$\quad$ - Custo operacional efetivo sem impostos & $\mathrm{R} \$ 2.635 .413,73$ \\
- Remuneração sobre o capital de giro & $\mathrm{R} \$ 42.062,89$ \\
Margem bruta & $\mathrm{R} \$ 208.708,45$ \\
Margem líquida & $\mathrm{R} \$ 161.921,30$ \\
Resultado & $\mathrm{R} \$ 56.392,56$ \\
Custo operacional efetivo/@ & $\mathrm{R} \$ 46,65$ \\
Custo operacional total/@ & $\mathrm{R} \$ 47,48$ \\
Custo total/@ & $\mathrm{R} \$ 49,34$ \\
Custo variável unitário/@ & $\mathrm{R} \$ 47,34$ \\
Preço médio de venda da @ & $\mathrm{R} \$ 50,06$ \\
Produção total & $56.561,57 @$ \\
Ponto de equilíbrio & $41.705,99 @$ \\
Lucratividade & $1,98 \%$ \\
Rentabilidade & $1,29 \%$ \\
Custo fixo / custo total & $4,06 \%$ \\
Custo variável / custo total & $95,94 \%$ \\
Custo com depreciação / custo operacional total & $1,74 \%$ \\
Custo operacional efetivo / custo operacional total & $98,26 \%$ \\
\hline
\end{tabular}

Tabela 4. Receitas do confinamento de bovinos de corte

\begin{tabular}{lccc}
\hline Produção & Quantidade & $\mathrm{R} \$$ & $\%$ \\
\hline Venda de animais & $56.561,57 @$ & $2.831 .191,17$ & 99,44 \\
Esterco & $1068 \mathrm{t}$ & $16.020,30$ & 0,56 \\
Total & & $2.847 .211,47$ & 100,0 \\
\hline
\end{tabular}

$@=$ arroba; $\mathrm{t}=$ toneladas

O custo operacional total, $\mathrm{R} \$ 2.685 .290,18$, foi obtido pela soma do custo operacional efetivo, representado pelo desembolso, e do custo de depreciação dos bens patrimoniais (Tab. 3). Embora não seja um desembolso, o valor referente à depreciação representa uma reserva de caixa, que deveria ser feita para reposição dos bens patrimoniais (instalações, máquinas, equipamentos etc.) ao final de sua vida útil. A receita do período permitiu que se fizesse essa reserva. Isso significa que ao final da vida útil dos bens, nas condições e/ou situações encontradas, o pecuarista teria recursos monetários para a aquisição de novos bens substitutos, sem se descapitalizar. A depreciação foi responsável por $1,7 \%$ do custo operacional total (Tab. 3). Embora na literatura não exista informação sobre qual seria um bom valor para esse indicador técnico, pode-se dizer que a eficiência de utilização dos bens do patrimônio do sistema de produção estudado foi semelhante à do sistema analisado por Lopes e Sampaio (1999), cujo valor foi de $1,6 \%$.

O custo operacional efetivo representou o desembolso médio feito pelo produtor para custear a atividade. Os itens que compuseram o custo operacional efetivo de produção são apresentados na Tab. 5. Essa divisão, de acordo com Lopes et al. (1999), permitiu o monitoramento e o detalhamento das despesas. 
Tabela 5. Contribuição de cada item no custo operacional efetivo do confinamento de bovinos de corte comparando com outros estudos

\begin{tabular}{lccc}
\hline Despesas & $\mathrm{R} \$$ & $\%$ & $\% *$ \\
\hline Animais & $1.805 .041,69$ & 68,41 & 67,87 \\
Alimentação & $588.818,03$ & 22,32 & 29,84 \\
Despesas diversas & $114.150,91$ & 4,32 & 1,04 \\
Mão-de-obra & $102.908,70$ & 3,90 & 0,51 \\
Sanidade & $24.494,40$ & 0,93 & 0,74 \\
Impostos fixos & $3.089,29$ & 0,12 & - \\
Total & $2.832 .160,37$ & 100,00 & 100,00 \\
\hline
\end{tabular}

*Dados obtidos em Lopes e Sampaio (1999).

A aquisição de animais representou $68,4 \%$ do total das despesas operacionais efetivas, valor semelhante ao obtido por Lopes e Sampaio (1999). Esse alto percentual mostra que o pecuarista deve dar maior atenção a esse quesito, pois uma pequena economia, sem deixar de lado a qualidade dos animais a serem confinados, representa redução considerável do custo operacional efetivo. Um ponto crítico importante foi a qualidade dos animais confinados. Isso ficou evidente no baixo desempenho deles, cujo ganho médio diário foi de $1,05 \mathrm{~kg}$.

A alimentação foi responsável por $22,3 \%$ das despesas operacionais efetivas. Embora esse valor tenha sido inferior aos $29,8 \%$ encontrados por Lopes e Sampaio (1999), que estudaram a rentabilidade de um confinamento de 1000 bovinos machos, os custos com alimentação volumosa poderiam ser reduzidos com o aumento da produtividade do capim-elefante (Pennisetum purpureum), que neste experimento foi de apenas $70 \mathrm{t}$ de matéria natural, em três cortes. Também na ração concentrada, constatouse que houve excesso de proteína e falta de energia em relação às exigências recomendadas para animais com peso médio de $430 \mathrm{~kg}$ e ganho diário de $1,1 \mathrm{~kg}$. Assim, o balanceamento da dieta é importante para diminuir custos. De acordo com Lopes (1997), uma opção para balancear rações, testando diferentes fontes de alimentos, é utilizar softwares desenvolvidos especificamente para esse fim.

Quanto ao custo da mão-de-obra, o percentual de 3,9 está bem acima do encontrado por Lopes e Sampaio (1999) (0,51). Provavelmente a freqüência de arraçoamentos, devido ao pequeno espaço disponível de comedouro (0,25m/animal), contribuiu para elevar o custo desse item. Neste caso, o ajuste do número de animais ao tamanho dos currais de engorda e ao comprimento do comedouro deve ser considerado. Isto pode inclusive influenciar a eficiência de ganho de peso.

As despesas com vacinas, antiparasitários e outros medicamentos representaram $0,93 \%$ do custo operacional efetivo, evidenciando que não se justifica economizar nesse item.

Foram consideradas despesas diversas aquelas que não se enquadraram nos grupos mencionados anteriormente, tais como combustível, energia elétrica, frete dos animais, taxas e impostos variáveis em função da produção, despesas com manutenção de benfeitorias, máquinas e equipamentos. $\mathrm{O}$ valor representou 4,3\%. Impostos considerados fixos como o ITR e IPVA representaram apenas $0,12 \%$ das despesas operacionais efetivas.

O custo total representou a soma dos custos fixos e dos custos variáveis. Os custos fixos, representados pela remuneração da terra, remuneração do capital investido, remuneração do empresário, impostos fixos (ITR e IPVA) e depreciação do patrimônio totalizaram $\mathrm{R} \$ 113.342,29$. Eles não representaram desembolso (com exceção dos impostos), mas representaram o que a atividade deveria remunerar para ser competitiva com outras atividades econômicas e não descapitalizar o pecuarista.

Pela análise de rentabilidade tem-se a margem bruta (receitas menos custo operacional efetivo). Ela mostra que a atividade se remunerou, pelo menos a curto prazo. A margem líquida (receita menos o custo operacional total) mostra que a atividade foi estável, com possibilidade de expansão ou de manutenção a médio prazo. A diferença entre as receitas e o custo total indica 
que a atividade foi lucrativa e pode-se manter a longo prazo.

A lucratividade foi de $2,0 \%$ e a rentabilidade $1,3 \%$. Pela lucratividade pode-se comparar com outros sistemas de produção de bovinos de corte; pela rentabilidade, com atividades diferentes. Como exemplo cita-se a caderneta de poupança, que no período de nove meses obteve taxa real de juros de $4,5 \%$, isto é, a atividade estudada foi melhor negócio para o pecuarista. Esse percentual foi utilizado na remuneração do capital investido.

\section{CONCLUSÕES}

Os componentes do custo operacional efetivo que exerceram maior influência sobre os custos da atividade estudada foram, em ordem decrescente: aquisição de animais, alimentação, despesas diversas, mão-de-obra, sanidade e impostos. $\mathrm{O}$ resultado final foi positivo, evidenciando que a atividade tem condições de sobreviver no longo prazo, inclusive se capitalizando. Alguns pontos críticos, se corrigidos, têm influência positiva na rentabilidade do sistema de produção.

\section{REFERÊNCIAS BIBLIOGRÁFICAS}

LACORTE, A.J.F. Principais aspectos do confinamento de gado de corte no Brasil. In: SIMPÓSIO DE PECUÁRIA DE CORTE: NOVOS CONCEITOS NA PRODUÇÃO BOVINA, 2., 2002, Lavras. Anais... Lavras, 2002. p.81-107.

LOPES, M.A. Informática aplicada à bovinocultura. Jaboticabal: FUNEP, 1997. 82p.

LOPES, M.A.; CAMPELLO, R.P.; CARVALHO, F.M. et al. Cu\$to bovino corte 1.0: software de controle de custos para a pecuária de corte. In: REUNIÓN DE LA ASOCIACIÓN LATINOAMERICANA DE PRODUCCIÓN ANIMAL, 27., 2001, Havana. Anais... Havana: ALPA, 2001. p.2076-2080 (CD-ROM).

LOPES, M.A.; CARVALHO, F.M. Custo de produção do gado de corte. Lavras: UFLA, 2002. 47p. (Boletim Agropecuário, 47).

LOPES, M.A.; JUNQUEIRA, L.V.; CARVALHO, F.M. et al. Desenvolvimento de um sistema computacional para determinação do custo de produção do gado de corte. Rev. Bras. Agroinf., v.2, p.105-116, 1999.

LOPES, M.A.; SAMPAIO. A.A.M. Manual do confinador de bovinos de corte. Jaboticabal: FUNEP, 1999. 106p

MARTINS, F.M.; LOPES, M.A. Análise de rentabilidade de um confinamento de gado de corte realizado no município de Lavras, sul de Minas Gerais. In: ENCONTRO DE INICIAÇÃO CIENTÍFICA, 7.; MOSTRA DE PÓSGRADUAÇÃO UNITAU, 3., 2002, Taubaté. Anais... Taubaté, 2002. p.94.

MARTINS, F.M.; MACEDO, S.V.; LOPES, M.A. Análise de rentabilidade de um confinamento de gado de corte realizado no município de Ijaci, sul de Minas Gerais. In: ENCONTRO DE INICIAÇÃO CIENTÍFICA, 7.; MOSTRA DE PÓS-GRADUAÇÃO UNITAU, 3., 2002, Taubaté. Anais... Taubaté, 2002. p.94.

MATSUNAGA, M.; BEMELMANS, P.F.; TOLEDO, P.E.N. et al. Metodologia de custo de produção utilizado pelo IEA. Agric. São Paulo, v.23, p.123-139, 1976.

PEIXOTO, A. M.; HADDAD, C. M.; BOIN, C. et al. $O$ confinamento de bois. 2.ed. Rio de Janeiro: Globo, 1988.

REIS, R.P. Introdução à teoria econômica. Lavras: UFLA/FAEPE, 1999. 108p. 